\title{
CS Research Square \\ Medical Student Perspectives on Substance Misuse Education in the Medical Undergraduate Programme: A Grounded Theory Approach
}

Senthan Rudrakumar ( $\sim$ senthan.rudrakumar@nhs.net )

University of Liverpool

David Taylor

University of Liverpool

\section{Research Article}

Keywords: Substance misuse education, addiction in medical school, informal learning, student voice, curriculum change

Posted Date: November 19th, 2021

DOI: https://doi.org/10.21203/rs.3.rs-1072543/v1

License: (c) (1) This work is licensed under a Creative Commons Attribution 4.0 International License.

Read Full License 


\section{Abstract}

\section{Background}

A substance misuse epidemic has been appropriately responded to in medical education. Numerous curriculum reviews and most recently a UK department of Health (DOH) project have identified deficiencies in substance misuse education whilst also suggesting an alternative curriculum to be implemented into UK medical school. The student perspective has largely been muted during this process and this study aims to explore this using a constructivist grounded theory approach.

\section{Methods}

Eleven Final year and intercalating medical students across three separate focus groups participated in this study. Focus groups were initially less structured with subsequent focus groups session using more guided questions. Audio recordings of focus groups were transcribed into codes and categories until data saturation was obtained.

\section{$\underline{\text { Results }}$}

Medical students had a common consensus that substance misuse education was an underperforming subject in their curriculum, from limited teaching hours to curriculum design and organisational problems. Students identified an alternative curriculum is required to not only prepare students for their future clinical duties but also their own personal lives. Students highlighted this proximity to a 'dangerous world' where exposure to substance misuse risks were faced daily. This exposure also provided a source of informal learning experiences which students deemed as being potentially unbalanced and even dangerous. Students also identified unique barriers to curriculum change with reference to a lack of openness due to the impacts of disclosure in substance misuse.

\section{Conclusion}

The student perspective identifies deficiencies in substance misuse education and provides alternative curriculum approaches like that discussed in current curriculum reviews and projects. The student perspective however provides a unique look at how substance misuse pervades into their own lives and how informal learning is a largely underestimated source of learning with more dangers than benefits. This together with the identification of unique barriers to curriculum change and substance misuse being a ubiquitous problem, medical faculties should work together with students themselves to drive curriculum change forward at a local level.

\section{Introduction}

The effects of dangerously high levels of substance misuse within the patient population, the medical profession and medical students, the question of whether medical schools are doing enough in terms of 
the teaching and learning of substance misuse; is brought to the forefront (Forster, 2017; llana B Crome, 1999; Hussein Rassool \& Oyefeso, 1993).

Substance misuse within medical education has not always been recognised as an important domain of study. However various reports by larger organisations ranging from the Royal College of Physicians to the World Health Organisation (WHO) have repeatedly referred to the need for improved teaching of substance misuse teaching and learning within medical education (WHO 2018; llana, 1989; Tomson, 1987). Health policy has reflected a progressive attitude towards addiction with greater acceptance and understanding of the prevalence of such issues (Ilana B Crome, 1999; Landy

et al., 2011). Medical education also reflected this change through incorporation of substance misuse within the General Medical Council (GMC) Tomorrow's Doctor Outcomes (2009); which outline the outcomes that must be incorporated into all UK medical schools. GMC outcome $1.9 \mathrm{~g}$ states that graduates should be able to; 'Identify and appropriate strategies for managing patients with dependence issues and other demonstrations of self-harm (GMC, 2009).'

A UK Government department of health (DOH) funded project initiated in 2005 aims to implement a coordinated substance misuse curriculum into all UK medical schools. The initiative consisted of three phases: Phase 1 (2005-2007) involved evaluation of current substance misuse teaching practices and deficiencies. The findings of phase 1 gave rise to a landmark substance misuse curriculum that outlined a uniform approach to teaching of substance misuse, orientated around 6 core learning topics (Table 1) which are then further broken down into more specific learning objectives. Phase 2 (2008-2011) consisted of appointing curriculum champions to each of the 32 medical schools for implementation to proceed at a local level. Phase 3 (2013 - ) looked towards sustaining those positive changes. The project concluded that training and education of student doctors had been enhanced and a solid basis for substance misuse teaching had been formed. The project stated that it had influenced the teaching and learning of at least 47,000 future doctors with benefits continuing to accumulate over time (Carroll et al., 2014; ICDP, 2007). 
1. Bio-psycho-social models of addiction

2. Professionalism, fitness to practice and students own health

3. Clinical assessment of patients

4. Treatment interventions

5. Epidemiology, public safety, and society

6. Specific disease and specialty topics

The DOH curriculum however was constructed with the joint effort of a steering committee that was made up of predominately specialist clinicians including addiction specialists and psychiatrists as well as individuals with an interest in medical education. The level of student involvement within the construction of the curriculum is limited and ambiguous based on the project report. Early researchers such as Crome (1999) who frequently re-visited the area of substance misuse education, pointed out that medical students should be part of the decisions and structures that go into improving the training for the next generation of trainees (Bovill, Morss, \& Bulley, 2009; Ilana B Crome, 1999). By making the student the key driver for change, barriers toward implementation are much more likely to be overcome. (Ilana B. Crome \& Shaikh, 2004). The top-down approach in the DOH curriculum project therefore misses a unique opportunity to explore student perspectives on substance misuse education, a health problem which is so different to many traditional curriculum topics because of its ubiquitous nature, which sees it potentially impacting both student's personal and professional lives (Pickard et al., 2000).

The objective of this study is to uncover the medical student's perspective on substance misuse teaching and learning within the undergraduate curriculum. This important perspective will aim to provide a useful lens to which to understand the subject area and provide useful information for policy makers, curriculum champions and medical educators when considering the implementation or development of substance misuse education. This will in turn aim to ensure the Doctors of tomorrow are equipped for a growing health problem particularly amongst the younger population (Fowlie 1999; NHS, 2018) and confidently managing substance misuse related problems in their future careers.

\section{Methods}

\section{Methodology.}

The methodology adopted for the research question is based upon the qualitative approach of Constructive Grounded Theory by Charmaz (2005). Exploring Medical student perspectives lends itself to 
a qualitative research approach. Naturally this will provide greater insight, richness, and depth to the data (Tolley et al., 2016) when compared to quantitative studies for this research question. The Grounded Theory approach, developed by Glaser and Strauss (1967) emerged during a period when qualitative analysis was largely seen as descriptive and less rigorous than quantitative research (Tobin \& Begley, 2004). In response, Glaser and Strauss aimed to legitimise qualitative research by clarifying and codifying their procedures and practices for data analysis, enabling qualitative research to attain levels of rigour along-side those already well accepted quantitative methods (Bryant, 2002).

Grounded theory is a useful methodology for areas of research where little is known about the topic. The approach centres around the creation of theory via a parallel process of data collection and analysis which informs further points of data collection by the emergence of new concepts and theories. This process continues until data saturation has been reached (Birks \& Mills, 2015; Charmaz, 2014).

Critiques of this approach however highlighted that the position of the researcher has potential to shape the emerging theory based on their own preconceived understanding of the subject area. The constructivist approach to grounded theory allows for the researcher to use their understanding as a tool to greater understand the research participants by remaining open yet facilitative in data collection. Constructive grounded theory considers the position of the researcher their role and perspective, rather than the positivist notion that the researcher is a dispassionate and external analyst who is distant from the research field (Charmaz, 2014; Watling \& Lingard, 1995).

\section{$\underline{\text { Researcher }}$}

The primary researcher and interviewer for this study was a final year medical student, with an interest in medical education and substance misuse education. The researcher's preconceived ideas were understood to be a source of potential involvement with theory emergence. This however provided a useful springboard for further concepts and ideas by pushing the level of theory emergence forward. The researcher had to be careful however not to guide participants into channels of their own thoughts and ideas.

\section{Study_population and recruitment}

Following approval of the project from the ethics board at The University of Liverpool, a series of small focus groups were designed to capture the perspectives of medical students. Ethical approval was provided for a series of up to four focus groups, each with between 3-8 participants per focus groups. Final year and intercalating medical students were selected as they were deemed collectively to have more experience of their own curriculum to draw back from. All participants $(n=11)$ were recruited from a single UK medical school allowing for three separate focus group sessions; at which point data saturation was reached. Participants were recruited via email with attached participants information sheets. Written consent was obtained from all participants prior to involvement in focus groups. 
Focus groups provided a psychologically safe domain and suitable approach to data collection for a subject area that has the potential to be of a sensitive nature. Focus groups provided an opportunity to for participants to bounce ideas and discuss ideas amongst themselves (Charmaz, 2006). Focus group sessions were carried out by the primary researcher who had experience and training in facilitating focus groups. A lead supervisor was also available for support and concerns. Sessions were audio recorded with consent from participants. Sessions lasted between 50 minutes to 90 minutes.

Applying the constructive approach, the first Focus group was centred around creating conversation. Charmaz (2014) suggested initial data collection should facilitate discussion and openness using a flexible approach without frequent prompt or interviewing questions. Following analysis of the first focus group additional guided questions were developed to explore emergent theory in subsequent focus groups until no new emergent categories were identified (see table 2)

Table 2 - Sample of focus group questions

First focus group - open questions with further follow up questions

What do you all think about the teaching of substance misuse in medical school?

- Can you recall any sessions you have had on substance misuse?

- Were these sessions helpful?

Why is it important to learn about substance misuse in medical school?

- Have you seen patients who had substance misuse related problems?

- Is it something you come across more often?

Would you change the way substance misuse was taught in medical school, and if so how?

- What kind of session would you create for medical students?

- You mention its not as easy as creating a cardiology session but why?

Second focus group - with guided questions in addition to $1^{\text {st }}$ focus group

Has medical school prepared you sufficiently to manage patients with substance misuse problems?

Do you feel medical school can address substance misuse related problems in student's personal lives?

If you were designing a new curriculum for medical students, how would you implement substance misuse education?

Do you feel there are any barriers in implementing this subject?

Third focus group - further guided questions in addition to $2^{\text {nd }}$ focus group

What other sources of learning apart from formal sources do you think students adopt regarding

substance misuse education?

Does the following Model of substance misuse education relate to you?

What does being streetwise mean to you?

Data coding and analysis

Audio recordings were transcribed after each focus group by the lead researcher onto a word processing platform. Initial line-by-line coding commenced by attaching 'gerunds' as described by Charmaz (2014) to 
ensure early codes remain objective and close to collected data (Appendix 1). This results in a large volume of fragmented codes obtained from continuous text.

A process of constant comparative analysis forms more focussed codes, where initial codes a refined and collapsed into larger codes (Appendix 2). Initial and focussed codes were also cross-checked by the research supervisor to ensure appropriateness of assigned codes.

Techniques such as Memo-writing and clustering were used to take 'lower-level concepts' to a higher level to provide more explanatory power and drive forward the emerging theory. Memo-writing is a note taking process as suggested by Charmaz (2014) that provides space for questions to formulate about obtained codes (Appendix 3 and 4). Charmaz suggested keeping a Chronological record of memos to reflect upon. Clustering is another technique which provides a non-linear, visual, and flexible method to understand and organise the data. (Appendix 5). Clusters can outline relationships of codes to each other and additionally highlight more central codes and thus start to produce tentative categories. Clustering makes use of the thoughts and questions that arise from memo-writing.

\section{Results}

Five Core categories were identified which encapsulated the data collected from three focus groups involving eleven participants (see Table 3). The framework suggested by Corbin and Strauss (1990) using core and sub-categories will be used to present the findings. Extracts from focus groups from participants will also be used to help outline the different sub-categories. 
Table 3

Core and subcategories of student perspectives

Core Category

1. Substandard substance misuse education: Unprepared to practice
Sub-Category

Curriculum design: Time and Organisation

Tick box exercise

Proportionality: importance vs time

2. Dangerous world: A wider societal problem

Substance misuse in public

Substance misuse in student life

Streetwise

3. Alternative approach to substance misuse education

4. Barriers to curriculum change

5. Informal Learning
Clinically relevant spiral curriculum

psychology of substance misuse

Teaching for today's society

Complex patient group

Impacts of disclosure: A need for openness

Baseline knowledge

Sources of informal learning

Dangers of informal learning

1. Substandard substance misuse education: unprepared to practice.

Participants were quick to reflect on their learning experiences of substance misuse topics and recognise the deficiencies of the subject in their curriculum. Students also related this to the bigger picture and the importance of this subject in terms of their position as future medical practitioners. This Large category is further divided into the following: Curriculum design, Tick box exercise and Proportionality.

Curriculum design: Time and organisation. Students reflected on individual teaching sessions involving substance misuse and recognised that sessions were very few and far between. Most students $(n=8)$ often struggled to recall any sessions at all, however following discussion and prompts by colleague's they were able to draw on specific teaching sessions. Students also reported that sessions were fragmented, occurring sporadically within certain rotations.

I think we have only had one teaching session on substance misuse, haven't we? That was in 4th year during our psych placement. That's all I remember. I remember it being a good session, and I remember 
learning about signs of withdrawal and what to do. Beyond that I cannot recall another lecture about it (Participant 2)

When I was on my psychiatric rotation, we could go on an optional addiction day which I was unable to attend, apparently it was quite a good session (Participant 1)

My CBL (case-based learning) session on addiction was just before my final exams and our tutor let us go early so, we could all revise for exams. I think it would have been better to have it earlier on in the year. (Participant 8)

The only teaching we had was when we were on psychiatry in 4th year, and I remember one lecture in 1st year about substance misuse and professionalism issues. I think it should be planned better, it's a matter of organisation. (Participant 3)

Tick box exercise Students recognised that during their medical school experience often topics which are more 'taboo' and less traditional were approached as a tick box exercise. Thus, using an easy solution for difficult societal problems.

We had to do these e-learning modules on addiction, self-harm, and female genital mutilation. I didn't find these engaging at all and didn't learn much from them. (Participant 3)

Yeah, I feel eL earning is now being used to tick off those taboo topics. It just helps with ticking a box for meeting a standard by the GMC (Participant 4)

Proportionality: Importance vs time

Participants being largely final year medical students, discussed their preparedness to manage substance misuse related problems next year as a junior doctor. They referred to the prevalence of the problem and high numbers of presentations and clinical workload in contrast the amount if teaching they have had on this subject area.

Substance misuse is a highly prevalent problem in community but has the least amount of teaching dedicated to it. Its something that in A\&E you will face (participant 8)

When I was on my A\&E placement, there was a lot of substance misuse related patients especially in the area surrounding my hospital. I feel university should prepare students for common things rather than rare conditions. (Participant 7 )

Asthma for example is a common widespread problem and taught well, using the same principle means drug usage can cause so many implications psychically and psychologically because of the impact and how large it can be. (Participant 2) 
2. Dangerous world: a wider societal problem

Participants discussed and debated in depth the wider societal evolution and substance misuse and described this concept of the 'Dangerous world' we now live in. Students explored substance misuse in public, substance misuse in the student life and being 'Streetwise'

Substance misuse in public Students explained that substance misuse was unlike any other health problem. Students described how they witness the impacts of substance misuse daily. These reflections often highlighted the proximity of students to the devastating impacts of substance misuse.

I mean its everywhere, especially in big cities such as Liverpool. I see it every day when I come home from hospital, people using drugs outside my house. They do it in broad daylight! (Participant 8)

Yeah, it's on our doorstep. It's a dangerous world and we need to be better prepared (Participant 11)

Substance misuse is a big problem here in Liverpool, I see so many patients in A\&E who have addiction problems or needing treatment for withdrawal. (Participant 5)

Substance misuse in student life This was a particularly interesting area of discussion in all three focus groups, as it pertained to the participant themselves. Students explained how substance misuse problems in students own lives is not something openly discussed in medical school largely due to professionalism concerns. Students explained how this can impact on students seeking help and even helping others. Students re-iterated the potential for substance misuse to pervade personal and family life.

I'm not going to lie, I heard about so many new drugs, like on nights out, people offer things to you and stuff. You just hear new random drugs that you've never heard of before. (Participant 10)

Everyone forgets we are human beings, and this could be an 18-year-old that has just come into university, and we are given a lecture on our first week saying, don't have Facebook, don't have Instagram, don't do drugs, don't do this. What happens when someone does do this? We are not told what to do (Participant 6)

I know people in my own family who have had problems with addiction and that it can affect older people too. (Participant 11)

Streetwise Students discussed how not only being prepared to treat patients but also to be ready to tackle societal problems and demands. For some students this meant being safe in situations where you are exposed to substance misuse and to other students this meant being able to respond to an unwell friend or member of the public and knowing what to do. 
I think we can be taught how to help a friend who is going through an addiction problem for example rather than just saying go and see a GP (Participant 7)

I think its important to be a bit streetwise and to know what's going on, especially as substance misuse is a growing problem (Participant 1)

Being able to respond to someone who might have taken a drug on a night out and has reacted badly would be very useful (Participant 11)

3. Alternative approach to substance misuse education

Having highlighted deficits in current teaching, students put forward ideas and subject themes that they felt were important to be implemented in a curriculum that reflects todays learning needs. Students also identified different methods of delivering sessions that would increase engagement. The alternative approach can be further divided into clinically relevant spiral curriculum, psychological understanding of substance misuse, teaching to reflect today's society.

Clinically relevant spiral curriculum

Participants felt that teaching should introduce basic theoretical underpinning principles in the early years of the curriculum. They also recognised the need to understand the clinical approach to substance misuse patients similar to that of other, more traditional subjects. Students suggested that this layered approach by introducing components into every year would lead to more sustained learning and a deeper understanding.

In the first couple of years, you can get a decent grounding on the drugs which are common. When you get to $3 r d$ or 4 th or 5 th year, you can then plan. Some GPs will have addiction clinics, so you can spend the day there (Participant 3)

So instead of just having one half an hour teaching in 4th year, having a couple of placements in addiction clinic (Participant 6)

It feels like, actually thinking about it, it should be its own block, next to the respiratory block. There is just so much to look at, so much out there. (Participant 8)

Psychology of substance misuse

Students often discussed the need to understand the narrative behind substance misusers and those with addiction problems. Students felt that by listening to patient experiences with different substances and 
appreciating their journeys, students will be able to get a better idea the psychology behind patient choices.

it is going to be different for different people but in general there are certain triggers that lie within a certain spectrum, so to be able to see patients with these actual experiences, who have gone through this. (Participant 5)

It's all well and good reading up about these things but they are very individual and sociological psychological things that you can't always really read about. You have to experience these things and see these things. (Participant 8)

Teaching to reflect today's society

Substance misuse was viewed as a topic that was dynamic and ever evolving. Students felt the curriculum should reflect this by having more foreword thinking approaches to teaching that reflect problems of today's society.

The issue with current teaching is that it's quite old school and didactic. You get some old professor teaching you about heroin; you get dilated pupils who get this ... in reality, since substances are constantly changing it need to be constantly updated too (Participant 11)

Some of these things are the party drugs they are always going to be there. It's quite important to know about these. I think something like spice, could go away next year, something else could come in which could replace this legal high (Participant 4)

information like what kind of drugs are more prevalent. Heroin becoming less common, talked about legal highs coming into fashion. He knew the trends. He knew how to recognise each of them. Showed us pictures of what they look like, what situations people take certain drugs in. what these drugs costs. (Participant 3)

\section{Barriers to curriculum change}

When considering alternative approaches to delivering substance misuse education, participants repeatedly highlighted the potential barriers when considering implementing this subject into the medical curriculum. This is further categorised into: Complex patient group, Impacts of disclosure, and Baseline Knowledge

\section{Complex patient group}

Participants highlighted that when introducing more patient experience led sessions or addictions clinics, that there was potential for unpredictability compared to other patient groups. Students also discussed how the interaction between student and patient with addiction problems maybe of a sensitive nature both for the patient but also for the student themselves. 
It's very hard for them to guarantee that they can sit you down in a group session with someone who has had a problem and tell you a story (Participant 7)

So, it's not as straight forward, as just getting people to come in. It's a difficult topic. You are dealing with un-predictable people. Just thinking about how hard it can be to organise these things, it would be a credit to the medical school if they can organise that (Participant 9)

Impacts of disclosure: A need for openness

Students felt the culture of fear and lack of openness in substance misuse matters has the potential to limit curriculum change. Students felt certain teaching environments such as group sessions may not be appropriate due to the risk of disclosures and subsequent professionalism concerns. Students also referred to patients or ex-substance misusers not being willing to share experiences due to the stigma attached with this.

Let's open up the communication, why is this happening, why are these social problems existing. I think this would be useful especially in our age cohort as well. (Participant 1)

Maybe if there was openness, it would be easier for medical students, or all students to come forward and things will be stopped earlier rather getting to that point where there is no return. Or maybe an addiction happens. (Participant 5)

Learning of each other, people will be a bit apprehensive because, everyone knows someone who takes drugs, and that person is not going to stand up in a session and discuss it. No one would want to be associated with that (Participant 8)

Baseline knowledge

Another barrier that emerged was the prior understanding of the subject area being highly variable. Students were aware that they all had different backgrounds and upbringings, and this can impact on the learning of this subject. There was a consensus that education must cater for this and aim to standardise the knowledge.

If you're brought up in a certain environment, when its culturally taboo, you can't really discuss it at home. So, it's probably more of an issue. If you've come across it and you have never, and you don't really know what it is and because you don't really have that sort of experience, you may find it more difficult to deal with. In that respect, it is on the medical school to teach to an adequate standard (Participant 4)

If you've gone to a school where it's not talked about, or you don't even see people in public doing it. Then your awareness will be less than a lay person, if it's not brought to your mind that these things exist, you shouldn't be shocked if you see someone in hospital who has taken 10 pills together. That's one of the key issues, everyone comes in not knowing about what a stroke is, everyone starts from the same 
baseline and learns simple things. But every has different baseline understandings of it. People know different things, and everyone need to be bought up to some sort of similar standard. (Participant 10)

I'm generalising but a lot of people who have come from different religious background or cultural backgrounds, they would have never even touched alcohol or even seen an alcoholic, that very shock itself of being in a room with a guy you don't have any connection with; not saying that any of us have a connection with drugs or anything but just understanding, how do I approach speaking to this person, it's quite important. (Participant 2)

5. Informal Learning Informal learning refers to the learning away from the formal institutional structures. In this case away from the hospital or medical school setting. Two further categories emerged from this: Sources of informal learning and Dangers of informal learning.

Sources of informal learning

Students reported a wide variety of sources of settings of this informal learning. This usually emerged following the identification of limited formal sources of teaching on this subject.

It's mainly from seeing people around us who may have gone through it, may know other people who have gone through it, like taken a drug, it ended badly, usually you hear the bad stories, so you hear, ah this happened to this person. (Participant 2)

I saw this TED talk online, this guy is quite a maverick and does what he wants. He used a presentation with only pictures, such us a picture of someone gurning on a drug, pictures of someone in a field. He used his own experience of when he lived in New Zealand. People sniff a lot of glue in New Zealand because it's very rural. Not in New Zealand but in Bangladesh. It's a good way to get high. He used anecdotal stories which were very interesting. (Participant 4)

I used to watch a lot of these VICE videos on YouTube. They show how drugs are made and sold. They also look at the latest drugs that are becoming more popular and talk about their effects. I remember also watching things like Trainspotting which shows quite well how someone with addiction problems lives and tried to stop using drugs. (Participant 10)

Dangers of informal learning

Despite recognition that informal sources of learning existed, students were aware that this can often have a negative consequence. Informal learning seemed to be associated with a highly one-sided viewpoint, with either extremely positive or negative connotations.

usually you hear the bad stories, so you hear, ah this happened to this person. Obviously, there are things like alcohol, even that can cause issues (Participant 8 ) 
I think that is a also a dangerous game, because you get a lot of people that are kind of uneducated toward drugs, and have a different opinion. A lot of people, almost make it into a fashion (Participant 5)

You hear a lot of people talk about drugs, and only mention the good parts. They tend to be the people who abuse drugs. Whereas if you get actual proper education on it, then you get the bad sides and the good sides. You never get the good sides, but you usually ge the bad sides. If you usually hear it from a friend, that has taken some sort of drug, you usually hear the good parts of it. So, a lot of people can research about it one th internet, where you hear the good stuff, but you never hear the bad stuff.

(Participant 10)

\section{Discussion}

The student perspectives and the emerging theory obtained from this study will be examined and utilised as a lens to which to view the current literature and understanding of substance misuse education. This lens will also look to examine the recent UK department of Health (DOH) substance misuse curriculum project from an alternative perspective.

The central core message that is clear from the student perspective and is also displayed in the suggested model of the student voice (figure 1 ) is this idea that an alternative curriculum not only has the potential to improve preparedness for managing substance misuse in a clinical environment but also preparing future doctors for dangers faced in their own personal lives.

Students are unanimous in outlining a lack of teaching time dedicated to substance misuse, with most students having limited recall of sessions. This appears consistent with prior research which carried out surveys of medical schools to obtain the number of teaching hours dedicated to substance misuse. (Ilana B Crome, 1999; Ilana, 1989; N. Miller et al., 2000). Surveys concluded that teaching hours were very limited with some medical schools only having 3-6 hours of dedicated teaching time in their programme. A survey of 98 medical schools from 1986-87 highlighted that teaching was restricted to a few specialties such as psychiatry; a concept evident in the student perspective with teaching often being described as fragmented and unorganised (Davis, Cotter, \& Czechowicz, 1988).

Exploring dedicated teaching time can be deemed as a rather crude outcome; the student perspective is able to take this further by exploring the idea of 'proportionality' which views the quantity of teaching in terms of the wider prevalence and likely clinical workload relating to substance misuse. Students describe a mismatch between the common place of substance misuse within society and the amount of teaching received. The $\mathrm{DOH}$ backed project is clear in its construction about the rising prevalence and trends in substance misuse with the report referring to substance misuse being a big health, social and economic problem (ICDP, 2007). The student perspective views the rising trends but from the point of view of 'tomorrows doctors' and highlights their concerns about preparedness to practice and manage substance misuse in the clinical setting. The student voice recognises the importance of the subject area not only being met in the way of volume, but also quality of teaching. Few students identified interesting and engaging sessions of teaching, with students identifying 'tick-box' style delivery methods such as online 
e-learning modules. This is an important concept to take forward when considering implementing findings from the $\mathrm{DOH}$ backed curriculum project, which makes limited reference to the nature of the implementation of stated learning objectives.

Limited substance misuse education provides a platform for participants to discuss the impacts of this on their professional lives, in terms of preparedness to practice, but also identifying the pervasiveness into their own personal lives. Students shift focus from the clinical environment to their own everyday lived experiences. With one in five 16-24-year-olds having used an illicit substance in the previous year (NHS, 2018), it is not surprising that final year medical students who fit a similar age cohort, experience this proximity to substance misuse related problems. The 'dangerous world' concept initially mentioned by a single study participant appears to encapsulate this proximity. It is important to note, no study participants reported having any substance misuse related concerns themselves or report any use of illicit substances. Students also felt that formal educational structures need to appreciate this dangerous world to mitigate these exposed risks and ensure a more 'streetwise' medical student.

Table 4

Learning objects from DOH project which appreciate the 'Dangerous World' Describe the risk factors for substance misuse in medical students and in health professionals Describe how substance misuse problems may affect a health professional's judgement, performance, and care of their patients

Describe the need to balance due concern for the health of a colleague with responsibilities for the safety and welfare of patients

Outline the role of the medical schools and the GMC in ensuring students' and doctors' fitness to practise

Describe the sources of help for students and doctors with drug and alcohol related problems The DOH curriculum project has suggested learning objectives under the title 'Professionalism, fitness to practice and students own health' with specific learning objects that address the 'dangerous world concept' (see Table 4). The learning objectives are clear in their understanding of the pervasiveness of substance misuse problems in students own personal lives. With previous literature focusing on rates of substance misuse amoungst medical students (Pickard, Bates, Dorian, Greig, \& Saint, 2000), the student voice provides a more explanatory lens by highlighting the dangers and risks constantly being faced. This voice emphasises the need to implement the above learning objectives (Table 4) to ensure tomorrows doctors are better prepared for this ever increasing 'dangerous world'.

With an awareness of the exposure to substance misuse from the student perspective, informal learning sources were increasingly apparent. Students understanding of substance misuse, a result of being exposed to this 'dangerous world' acting as a source for informal learning itself. The DOH curriculum project makes clear that one of the study limitations was the exploration of informal learning sources that students are exposed to (ICDP, 2007). The student perspective identified specific informal learning sources, and the consensus was that the informal learning often had a biased undertone and was 
deemed subjective based on the source of the informal learning. Students were aware that their knowledge had the potential to be unbalanced and potentially 'Dangerous'.

Limited formal substance misuse education naturally provides space for informal learning sources to gain in strength. Hager (1998) outlined how Informal learning is highly contextual and often learners are influenced by prevailing assumptions about knowledge with an unawareness of their range and depth in informal learning (Hager, 1998). Formal education therefore must appreciate this sphere of learning by not only formalising the informal learning but to challenge student assumptions and pre-conceived understanding about substance misuse. Revealing the informal social side to learning in this subject area as described by Hommes (2012) can be crucial when designing individual learning sessions which can provide an open space to utilise this sphere of learning.

An alternative curriculum put forward by study participants addressed shortcomings in their own curriculum but also looked to address the 'Dangerous world' as visualised in the student voice model (Figure 1). Students discussed their alternative curriculum from a curriculum design standpoint as well as content standpoint. Students expressed a definitive need for not only more teaching but organised teaching that builds in competency throughout the clinical years. Research has shown that faculties with 'above average' hours taught in substance misuse, student's negative attitude towards substance misuse patients diminished between the first and last year of study (Landy, Hynes, Checinski, \& Crome, 2005). However, the long-term transferability is more questionable regarding changes in attitude and knowledge to later years (Johnson et al., 2014). The DOH curriculum project report refers to co-ordinating the content, delivery, and assessment, by ensuring core outcomes are covered at appropriate points to ensure a 'joined-up' approach for students. This will be facilitated by curriculum champions at faculty level with the aim of enabling long term consistent changes (ICDP, 2007).

The student voice highlighted that content within the alternative approach to be structured around the bio-psycho-social model. Clinically relevant teaching, preparing students for managing patients in their future careers whilst an understanding of the psycho-social underpinnings of substance misuse to prepare students to navigate the 'dangerous world'. The DOH curriculum project's first core topic, 'Biopsycho-social models of addiction' appears to address this very perspective. The $\mathrm{DOH}$ curriculum and the six core topics (Table 1), encompasses an extensive list of learning objectives that are not only clinically relevant but also address the psycho-social aspects to substance misuse.

Despite this the DOH curriculum does little in the way of describing suitable delivery methods of the described learning objectives. Students expressed how experiential learning rather than didactic methods were required. For example, designated clinical attachments. Existing research outlines how addiction placements are linked with a definite positive attitudinal shift towards substance misuse patients leaning to more long term and sustained change (Christison \& Haviland, 2003). Literature also highlights individual learning interventions in relation substance misuse which range from skills-based workshops with substance misuse patients to use of simulation for communication skills (Eagles, Calder, Nicoll, \& 
Walker, 2001; Lewis, 1990). There is still little concrete agreement towards the best way to teach this area of study (Gopalan, Santora, Stokes, Moore, \& Levine, 1992).

Existing literature and the $\mathrm{DOH}$ curriculum project however make little reference to the student voice calling for teaching and learning to reflect today's society. The DOH curriculum project does refer to being aware of UK policy and legislation around misuse of drugs and controlling drugs, but the call for teaching to outline current trends and to be ever evolving in order to be representative of society appears to be only partially reflected in the $\mathrm{DOH}$ curriculum report.

Increasing recognition of the importance of substance misuse education and recent curriculum developments have not necessarily led to effective curriculum change as evident in the student voice. Barriers to implementation in substance misuse have previously been identified primarily from a 'topdown' approach from the perspectives of medical school deans, clinicians and curriculum leads. These barriers include the medical model of addiction not being appreciated, cuts on psychiatry placements, medical students not given top priority and finally the potential emotional impact of substance misuse education on students with personal or family history of addiction problems (llana B Crome, 1999; Ilana B. Crome \& Shaikh, 2004; N. S. Miller et al., 2001; A. Paton, 1992). The student voice identified further areas of resistance including the impacts of disclosure involved with substance misuse and students having differing amounts of prior understanding of substance misuse knowledge, owing to the highly contextual and informal nature of the subject. The barriers identified and the sources of informal learning obtained from the student voice, seem to sit along a continuum between the alternative curriculum and its responsiveness to the students concern about their current substance misuse teaching and the dangerous world. The DOH curriculum project makes little reference to barriers to curriculum change in their project report.

\section{Implications for research}

Existing research recognises that substance misuse education is an important subject theme to be delivered in medical schools and often understands that dedicated teaching time on this subject is limited. Research predominately focusses on assessing the perspectives of curriculum leads, clinicians and faculty staff. The landmark DOH curriculum project which outlines a substance misuse curriculum to be adopted by UK medical schools shows limited representation of the student perspective in its initiation and design, however the curriculum put forward appears to encapsulate much of the student voice obtained from this study.

The student perspective obtained from this study appears consistent with the perspectives obtained in existing research from the $\mathrm{DOH}$ curriculum project. This further emphasises the urgency and need to incorporate substance misuse education within the medical curriculum. The student voice re-iterates the lack of substance misuse education but proceeds further by putting this in perspective of the importance of the subject to their future careers and personal lives. The concept of the 'dangerous world' portrays how close and exposed medical students are towards the risks of substance misuse in everyday life. This unique voice can aid local medical faculties in delivering the learning objectives from the $\mathrm{DOH}$ curriculum 
project in methods that not only address required clinical competencies but also the personal life dangers and risks towards substance misuse. This close proximity to substance misuse also provides a more explanatory lens as to reasons for substance misuse amongst medical students which can aid well-being teams and professionalism panels appreciate the problems commonly faced by students in today's society.

The student voice identifies unique barriers to curriculum change not expressed by other voices within this field and can therefore be utilised by curriculum leads and faculties when implementing alternative curriculums. Informal learning in substance misuse education, a theme not explored by previous research nor the DOH curriculum project has identified potential risks with this sphere of learning for this topic. Informal learning sources must therefore be appreciated and approached with caution to understand students pre-conceived ideas and to provide a formal structure to openly discuss and challenge these notions.

\section{Limitations and further research}

The study was carried out in a region of the UK with a particularly high rate of substance misuse amongst the general population which may therefore not be representative if a similar study was undertaken in a different region. Additionally final year students were predominantly included in study sample, with the aim of identifying individuals who had experienced a greater proportion of their curriculum. This approach may not provide a representative view of the whole medical student cohort, for example, concepts such as preparedness for practice, may not emerge from junior medical student perspectives.

A further limitation and interestingly an identified barrier for curriculum change was the potential impacts of disclosure. Focus groups remained open and undirected initially and thus providing space for free discussion. Participants being medical students could potentially be averse from discussing matters which may run the risk of any professionalism concerns being directed towards themselves. This not only re-iterates the barrier created by a lack of openness, but the sensitive and confidential nature required when continuing to further develop research initiatives in substance misuse within medical education.

\section{Conclusion}

Substance misuse teaching within the undergraduate programme has been understood as an increasingly underrepresented area of learning. This has provided scope for research to examine methods to implement an alternative approach from the perspective of clinicians, faculty staff and curriculum organisers. The constructivist grounded theory approach explored the perspectives however of medical students on substance misuse education and revealed a central principle that substance misuse curriculum must not only focus on preparedness for practice but preparedness for the dangers of substance misuse within daily life. This voice was in tune with other key stakeholder perspectives within the $\mathrm{DOH}$ backed curriculum project which reflects these views in its six core topics (Table 1). The student perspective also highlighted domains not reflected by other stakeholders including the identification of a 
largely underestimated source of informal learning as well as unique barriers to curriculum change. These two key areas together with substance misuse being a highly pervasive problem into students own personal lives, emphasises how medical faculties must work in tandem with students in designing and implementing substance misuse education at a local level.

\section{Abbreviations}

DOH - Department of Health

UK - United Kingdom

\section{Declarations}

\section{Ethics approval and consent to participate}

Ethical approval was granted by the University of Liverpool Health and life sciences ethics committee on 11/05/2018 - (please see ethical approval letter)

This study was carried out in accordance with the above ethical approval obtained. All methods were carried in accordance with the relevant guidelines and regulation

Informed consent was obtained from all study participants with consent forms signed by all eleven participants.

\section{Consent for publication}

Participant consent forms included the possibility of publication following completion of study.

Availability of data and materials

The datasets generated and/or analysed during the current study are not publicly available due to participant confidentiality as per consent obtained from participants. However anonymised and restricted focus group transcripts are available from the corresponding author on reasonable request

\section{Competing interests}

Author has no competing interests

\section{Funding}

No formal sources of funding for this project

Authors' contributions 
Lead researcher: SR - proposed study, undertook data collection and analysis of data and subsequent writing up of analysis and results.

Supervisor: DCMT - facilitated ethical approval process and provided critical feedback throughout the process.

All authors have read and approved the manuscript

Acknowledgements

Not applicable

\section{References}

1. Birks, M., \& Mills, J. (2015). Grounded theory: A practical guide: Sage.

2. Bovill, C., Morss, K., \& Bulley, C. (2009). Should students participate in curriculum design? Discussion arising from a first year curriculum design project and a literature review. Pedagogical Research in Maximising Education, 3(2), 17-25.

3. Bryant, A. (2002). Re-grounding grounded theory. Journal of Information Technology Theory and Application (JITTA), 4(1), 7.

4. Carroll, J., Goodair, C., Chaytor, A., Notley, C., Ghodse, H., \& Kopelman, P. (2014). Substance misuse teaching in undergraduate medical education. BMC medical education, 14(1), 34.

5. Charmaz, K. (2006). Constructing grounded theory: A practical guide through qualitative analysis: Sage. Charmaz, K. (2014). Constructing grounded theory. Sage.

6. Christison, G. W., \& Haviland, M. G. (2003). Requiring a One-Week Addiction Treatment Experience in a Six-Week Psychiatry Clerkship: Effects on Attitudes Toward Substance-Abusing Patients. Teaching and Learning in Medicine, 15(2), 93-97. doi:10.1207/S15328015TLM1502_04

7. Crome, I. B. (1999). The Trouble with Training: substance misuse education in British medical schools revisited. What are the issues? Drugs: education, prevention and policy, 6(1), 111-123.

8. Crome, I. B., \& Shaikh, N. (2004). Undergraduate medical school education in substance misuse in Britain iii: can medical students drive change? Drugs: Education, Prevention \& Policy, 11(6), 483-503. doi:10.1080/09687630410001701322

9. Davis, A. K., Cotter, F., \& Czechowicz, D. (1988). Substance abuse units taught by four specialties in medical schools and residency programs. Journal Of Medical Education, 63(10), 739-746.

10. Eagles, J. M., Calder, S. A., Nicoll, K. S., \& Walker, L. G. (2001). A comparison of real patients, simulated patients and videotaped interview in teaching medical students about alcohol misuse. Medical Teacher, 23(5), 490-493. doi:10.1080/01421590120075733

11. Forster, K. (2017). NHS doctors turning to substance abuse amid rising levels of stress and burnout. Independent. Retrieved from https://www.independent.co.uk/news/health/nhs- 
doctorssubstance-abuse-stress-burnout-rising-gps-addiction-health-service-bma-claregeradaa7805571.html

12. Fowlie, D. G. (1999). The misuse of alcohol and other drugs by doctors: a UK report and one region's response. Alcohol and alcoholism, 34(5), 666-671.

13. Glaser, B. G., \& Strauss, A. L. (1967). The Discovery of Grounded Theory: Strategies for Qualitative Research: Aldine.

14. GMC. (2009). Tomorrow's Doctors Retrieved from https://www.gmc-uk.org/Tomorrow_s_Doctors_1214.pdf_48905759.pdf

15. Gopalan, R., Santora, P., Stokes, E. J., Moore, R. D., \& Levine, D. M. (1992). Evaluation of a model curriculum on substance abuse at The Johns Hopkins University School of Medicine. Academic Medicine: Journal Of The Association Of American Medical Colleges, 67(4), 260-266.

16. Hommes, J., Rienties, B., de Grave, W., Bos, G., Schuwirth, L., \& Scherpbier, A. (2012). Visualising the invisible: a network approach to reveal the informal social side of student learning. Adv Health Sci Educ Theory Pract, 17(5), 743-757. doi:10.1007/s10459-012-9349-0

17. ICDP. (2007). Substance Misuse in the Undergraduate Medical Curriculum. Retrieved from https://www.sgul.ac.uk/images/docs/idcp\%20pdfs/Substance\%20misuse\%20in $\% 20$ the $\% 20 \mathrm{u}$ ndergrad\%20medical\%20curiculum/Substance_Misuse_Guidance_Undergraduate_Medical_ Curriculum_2007.pdf

18. Ilana, G. (1989). Undergraduate Training in Substance Abuse in the United Kingdom. British Journal of Addiction, 84(2), 197-202. doi:doi:10.1111/j.1360-0443.1989.tb00569.x

19. Johnson, J. A., Seale, J. P., Shellenberger, S., Velasquez, M. M., Alick, C., \& Turk, K. (2014). Impact of a medical student alcohol intervention workshop using recovering alcoholics as simulated patients. Advances in Medical Education and Practice, 5, 133-139. doi:10.2147/AMEP.S56176

20. Kothari, D., Gourevitch, M. N., Lee, J. D., Grossman, E., Truncali, A., Ark, T. K., \& Kalet, A. L. (2011). Undergraduate Medical Education in Substance Abuse: A Review of the Quality of the Literature. Acad Med, 86(1), 98-112. doi:10.1097/ACM.0b013e3181ff92cf

21. Landy, J., Hynes, J., Checinski, K., \& Crome, I. B. (2005). Knowledge of and attitudes to substance misuse in undergraduate British medical students. Drugs: education, prevention and policy, 12(2), 137-148.

22. Lewis, D. C. (1990). Medical education for alcohol and other drug abuse in the United States. CMAJ: Canadian Medical Association Journal = Journal De L'association Medicale Canadienne, 143(10), 1091-1096.

23. McGivney, V. (1999). Informal Learning in the Community: A Trigger for Change and Development.

24. Miller, N., Sheppard, L., Yang, L., \& Magen, J. (2000). A survey of curriculum for alcohol and drug disorders in medical schools througout the United States [unpublished]

25. Miller, N. S., Sheppard, L. M., Colenda, C. C., \& Magen, J. (2001). Why physicians are unprepared to treat patients who have alcohol- and drug-related disorders. Acad Med, 76(5), 410-418. 
26. NHS. (2018). UK Statistics on Drug misuse Office, H. (2017). Drug Misuse: Findings from the 2016/17 Crime Survey for England and Wales. Retrieved from https://assets.publishing.service.gov.uk/government/uploads/system/uploads/attachment_ data/file/632158/drug-misuse-2017-hosb1117snr.pdf.

27. Paton, A. (1984). Undergraduate survey of medical education in alcoholism

28. Paton, A. (1992). Barriers to education about alcohol. Journal Of The Royal Society Of Medicine, 85(8), 476-478.

29. Pickard, M., Bates, L., Dorian, M., Greig, H., \& Saint, D. (2000). Alcohol and drug use in second-year medical students at the University of Leeds. Med Educ, 34(2), 148-150.

30. Strauss, A., \& Corbin, J. M. (1990). Basics of qualitative research: Grounded theory procedures and techniques: Sage Publications, Inc.

31. Tobin, G. A., \& Begley, C. M. (2004). Methodological rigour within a qualitative framework. Journal of advanced nursing, 48(4), 388-396.

32. Tolley, E. E., Ulin, P. R., Mack, N., Succop, S. M., \& Robinson, E. T. (2016). Qualitative methods in public health: a field guide for applied research: John Wiley \& Sons.

33. Tomson, P. (1987). A GREAT AND GROWING EVIL: The medical consequences of alcohol abuse. The Journal of the Royal College of General Practitioners, 37(303), 469-469.

34. Varga, M., \& Buris, L. (1994). Drinking habits of medical students call for better integration of teaching about alcohol into the medical curriculum. Alcohol and alcoholism, 29(5), 591-596.

35. Watling, C. J., \& Lingard, L. (2012). Grounded theory in medical education research: AMEE Guide No. 70. Medical Teacher, 34(10), 850-861.

36. WHO. (2018). Substance Abuse Retrieved from http://www.who.int/topics/substance_abuse/en/

\section{Figures}




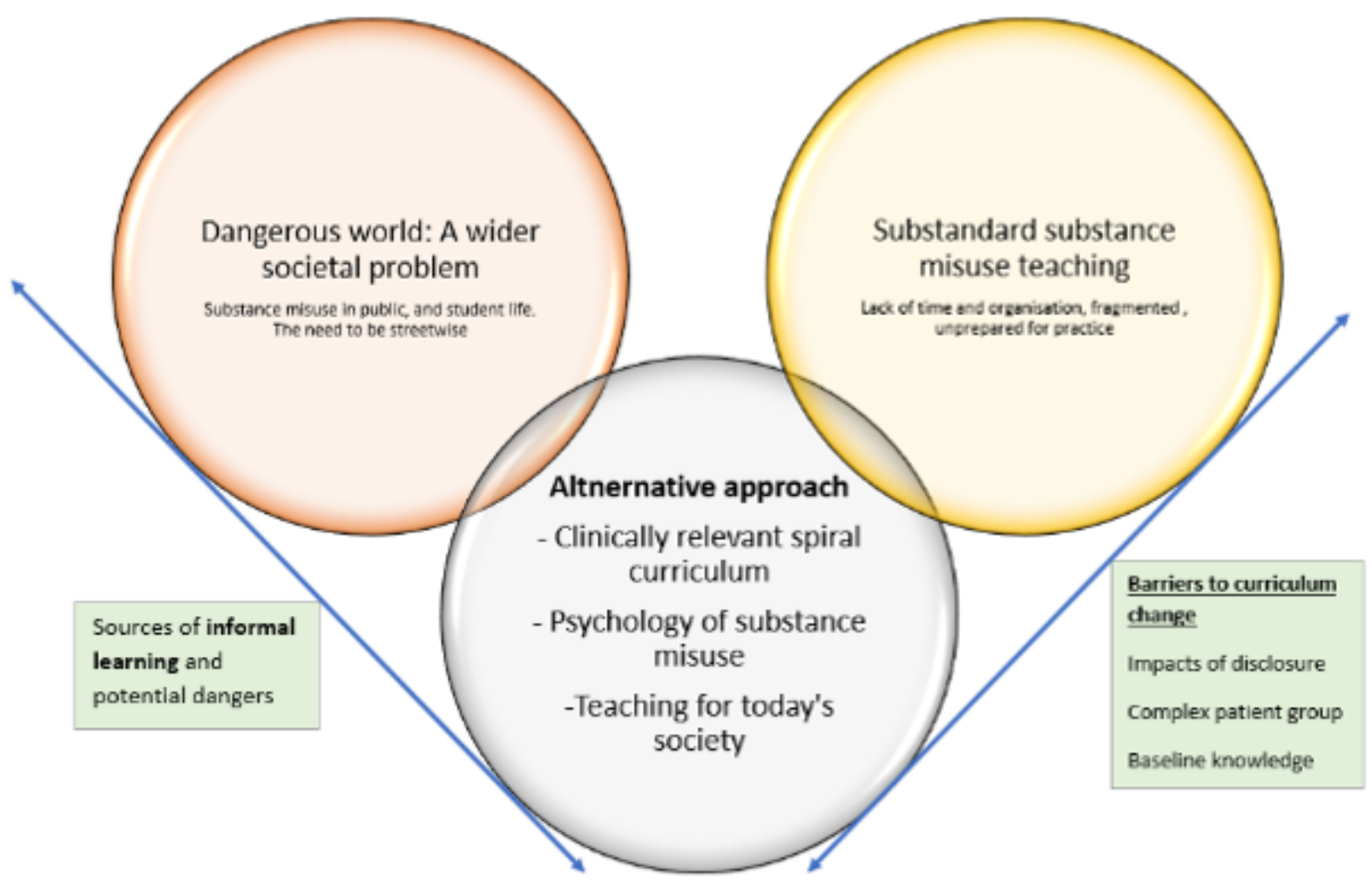

Figure 1

Suggested Model to represent Student voice on substance misuse education

\section{Supplementary Files}

This is a list of supplementary files associated with this preprint. Click to download.

- Appendix.docx 